Research Article

\title{
Effect of the VAN Hiele Instructional Model on Students' Achievement in Geometry
}

\author{
Edward Yalley, ${ }^{1}$ Gloria Armah, ${ }^{1}$ and Richard Kwame Ansah $\mathbb{D}^{2}$ \\ ${ }^{1}$ Department of Mathematics Education, University of Education, Winneba, Ghana \\ ${ }^{2}$ Department of Mathematics and Statistics, University of Energy and Natural Resources, Sunyani, Ghana \\ Correspondence should be addressed to Richard Kwame Ansah; richard.ansah@uenr.edu.gh
}

Received 14 June 2021; Revised 1 November 2021; Accepted 22 November 2021; Published 22 December 2021

Academic Editor: Enrique Palou

Copyright (C) 2021 Edward Yalley et al. This is an open access article distributed under the Creative Commons Attribution License, which permits unrestricted use, distribution, and reproduction in any medium, provided the original work is properly cited.

The purpose of this study was to determine the effect of the Van Hiele instructional model on students' achievement in Circle Geometry at Daffiama Senior High School in the Daffiama-Bussie-Issa District of the Upper West Region in Ghana. The purposive and simple random sampling techniques were employed to select a sample of 75 participants for the study. The sample involved two groups: the experimental group and the control group. While teaching based on the Van Hiele model was carried out in the experimental group, teaching with the traditional method was carried out in the control group. The study employed a quasiexperimental research design. The instruments used for data collection were tests, interviews, and classroom observation. Findings from the data analysis suggested that participants were at the prerecognition level before the intervention, improved from the prerecognition level to level 2 after the intervention as the model facilitated learning. It was recommended that teachers determine the geometric thinking levels of students before instruction; the Van Hiele learning and instructional model is adopted in curriculum design and applied in the teaching of geometry and other areas of mathematics.

\section{Introduction}

In the world all over, a strong culture of mathematics in a nation contributes to building a strong industrial culture. For this reason and many more, mathematics is made a compulsory subject from preschool to secondary level in almost every country in the world.

In Ghana, the Ministry of Education (MoE) through the National Council for Curriculum \& Assessment (NaCCA) and the Curriculum Research and Development Divison (CRDD) of the Ghana Education Service (GES) has developed a syllabus for mathematics which is based on the premise that "all students can learn mathematics and that all should learn mathematics" $[1,2]$. The move was part of efforts by the government to develop a strong human resource for the nation's economic growth. However, this move has not been without challenges. There are several reasons that had been attributed to the poor state of affairs in mathematics. According to Adolphus [3], these reasons include poor teaching of mathematics in primary, junior, and senior high schools, lack of motivation and incentives, and poor employment prospects in mathematics in many sections of the economy other than teaching. As a result, most students show gross disinterest in the subject and may not see it as a possible career path worthy of consideration. As part of the current government efforts to address the situation, the National Curriculum Framework (NCF) was released by the NaCCA in May 2018. This was part of the process where the present school curriculum is being reviewed to respond to a national priority of shifting the structure and content of the educational system from merely passing examinations to building character, nurturing values, and raising literate, confident, and engaged citizens who can think critically according to National Curriculum Framework [4].

In April 2006, Ghana joined other West African English-speaking (Anglophonic) countries to take the West African Senior School Certificate Examination (WASSCE). Consistently, it has been revealed by Chief Examiners Reports that students continue to perform 
poorly in mathematics nationwide according to [5-7]. However, a good number of the reports identify geometry as a weakness of most Ghanaian students. WAEC, for example, identified "solving problems involving geometry and trigonometry" as the number one weakness of students [5]. Although geometry forms a good percentage of topics Ghanaian students need to learn in preparation for its usage in life, it was found in WASSCE examinations that most students are found wanting with geometryrelated problems. According to Van Hiele [8], students' ability in mathematics is connected to their level of geometrical conceptual ability. However, despite the concerns of Asemani et al. [9] as well as other scholars about the teaching and learning of geometry in Ghana, many teachers continue to employ the traditional chalk and talk method in the geometry classroom.

Moreover, many researchers including Oladosu [10] and Asemani et al. [9] point to an inability to analyze identified geometric properties and a lack of understanding of formal geometric concepts among others as some difficulties that students face while learning geometry. These difficulties shape the learning process and meanings that students acquire from the learning experience in and out of the geometry classroom.

In Daffiama Senior High School, the situation is not different as students have challenges dealing with geometry. There is a consistent low performance in mathematics in WASSCE over the years. For instance, an analysis of the schools' performance in core mathematics revealed that only $2.62 \%$ of 382 candidates, $5.44 \%$ of 294 candidates, and $31.36 \%$ of 287 candidates had passed (C6 or better) in the years 2017, 2018, and 2019, respectively. While several factors may contribute to these low performances, the researcher believes teachers should not continue with new geometric topics until students' geometric levels are determined. Moreover, the traditional chalk and talk method of teaching mathematics in Ghanaian schools should be reviewed.

The works of Van Hiele [11], Adolphus [3], and Abdullah and Zakaria [12] assert that students' difficulties associated with geometry learning have been rectified in some Western countries and few African nations who have used the Van Hiele's Model (VHM) of learning in geometry effectively to improve performance of students in geometry. The model also helped inform curriculum developers and teachers about its importance in developing geometric tests. The theory proposes five levels through which students must experience sequentially in order to build a concrete understanding of the systems of relationships between geometric ideas. These five levels form the framework for the Van Hiele Instructional Procedure (VHIP). According to Vojkuvkova [13], the Van Hieles initially numbered them from 0 to 4, but later, the USA introduced numbering from 1 to 5. Although Pierre Van Hiele used only 3 levels, the level labels vary at present. These five levels are as follows:

\section{(i) Level 0 (visualization)}

Learners are able to recognize geometric shapes based on appearance rather than their properties. (ii) Level 1 (descriptive/analytical)

Learners are able to recognize characteristics of shapes and learn to use appropriate vocabulary related to these characteristics.

(iii) Level 2 (abstract/rational)

Learners can identify relationships between and among properties of shapes or classes of shapes. Also, they are able to follow logical arguments using such properties.

(iv) Level 3 (deduction)

Learners are able to construct geometric proofs using postulates or axioms and definitions. A student can take a high school geometry course at this level.

(v) Level 4 (rigor)

This is the highest level in the model. Students are able to work in distinct geometric systems.

The Van Hiele Geometric Test (VHGT) has also improved the students' geometric thinking levels in the countries which have adopted it [3].

Hence, this research seeks to determine the effect of the Van Hiele instructional model (VHIM) on students' achievement in Circle Geometry at Daffiama Senior High by addressing the following questions:

(1) Determine the Van Hiele geometric thinking level of students.

(2) Examine whether the Van Hiele instructional model has an effect on students' achievement.

(3) Determine whether the Van Hiele instructional model facilitates the learning of circle geometry.

\section{Methodology}

In this research, a pretest-posttest quasi-experimental design was employed. The pretest-posttest quasi-experimental design was suitable because the researcher aimed at determining the effect of teaching circle geometry based on Van Hiele's module. Furthermore, Cohen et al. [14] referred to the work of Kerlinger who described quasi-experimental designs as a suitable method for educational research where a random selection of schools or classrooms may be a challenge. Both qualitative and quantitative data collection procedures were employed. That is, an observation checklist (APPENDIX A) was used for qualitative data collection and a test item (APPENDIX B) was used for quantitative data collection. The researcher believed that triangulating data from the two approaches will best serve the purpose of this research.

The population consists of students of Daffiama Senior High School in the Daffiama-Bussie-Issa district of the Upper West region of Ghana. The school was chosen because students from different kinds of cultures and backgrounds made up the population of the school. The second-year students of Daffiama Senior High School were sampled for the study because students at this level 
are assumed to have acquired the requisite knowledge to learn circle geometry. This was a form of "convenience" sample. According to Cohen et al. [14], a convenience sample is one where a group of participants are selected because of availability. There are one thousand one hundred and twenty-three (1123) students in the school. Daffiama Senior High School is a mixed school and the only SHS in the Daffiama-Bussie-Issa District of the Upper West Region. In this study, the SHS 2 (grade 11) learners in the Daffiama Senior High School were targeted. This was because the researcher assumed that at that level students had acquired the requisite knowledge to learn circle geometry. Data from the management of the school indicates that the school has a total of three hundred and seventy-seven (377) SHS 2 learners in the academic departments: Arts, Home Economics, and Agricultural. Out of this number, one hundred and ninety (190) are boys and one hundred and eighty-seven (187) are girls. The accessible population was one hundred and twenty-four (124) students in grade 11 classes of Daffiama SHS: 2B, 2E2, and 2A2. These classes were used for the study because the researcher was assigned to teach those classes. Therefore, two intact classes (groups) of Daffiama SHS were matched to form the samples. Out of these classes, seventy-five (75) students were selected as a sample for this study. Thus, a total of 75 students from the two (2) intact classes formed the sample for the study. Students in the experimental group were forty (40) while those in the control group were thirty-five (35) in number.

2.1. Research Instrument. Fraenkel and Wallen [15] defined an instrument as any device used to collect data for the purpose of research. They explained that these instruments include questionnaires, interviews, tests, and observation. In this research, a geometric test and an observation checklist were the basic instruments used for gathering data. The test items contained three (3) main essay-type problems with three (3) subquestions each on circle geometry concepts. Each main question was based on the Van Hiele Geometric Test items as designed by Usiskin [16] and adapted by Baffoe and Mereku [17]. The test items tested the students' ability to identify and draw shapes out of a circle, use appropriate notations, symbols, and terminologies for both oral and written purposes, use the properties of the identified shapes to show equality of sides or angles, and use logical reasoning that may lead to the discovery of circle geometry concepts. For the purpose of data analysis, the test items were categorized into category 1 , category 2, and category 3 (see Table 1) according to the Van Hiele geometric learning. Moreover, the subquestions for each test item were designed to cater to the Van Hiele levels. The checklist was employed to check if the classroom lessons complied with the steps (based on the VHIM) taken and whether teaching was consistent with the VHIP. This was achieved by going through the recorded classroom observation data and marking the items in the checklist that was covered by the teacher as "yes," "no," or "nonapplicable."
TABLE 1: Question category and item.

\begin{tabular}{lcc}
\hline Category (question items) & Subquestion & Van Hiele level \\
\hline 1 & (a) & 0 \\
2 & (b) & 1 \\
3 & (c) & 2 and 3 \\
\hline
\end{tabular}

\section{Results and Discussion}

3.1. Data Analysis. The Van Hiele geometric thinking level of the participating groups was as follows.

Table 2 shows the performance of participants on subitems "a" in the pretest. All those items are at Level 0 of the Van Hiele Geometric Thinking Levels.

Table 2 shows that out of the 75 participants, only 18 (24.0\%) were able to answer correctly subtest (a) of question one (1). Also, $6(8.0 \%)$ answered correctly subtest (a) of question two (2). Finally, only 7 (representing 9.0\%) answered correctly subtest (a) of questions three (3).

Table 3 shows the performance of participants on subitems "b" in the pretest items. All such items were at Level 1 of the Van Hiele Geometric Thinking Levels.

From Table 3, it can be seen that out of the 75 students, only 61 (representing 81.3\%), 5 (representing 6.7\%), and 37 (representing 49.3\%) answered correctly subtest (b) of questions 1,2 , and 3, respectively.

Performance on Subtest Questions (c): Level 6.

Table 4 indicates that out of the 75 students, only 13 (representing17.3\%), 11 (representing 14.7\%), and 5 (representing 6.7\%) answered correctly subtest (c) of questions 1,2 , and 3 , respectively. The reader should also note that subtest "c" of question 2 also tested up to level 3 of the VHGT.

3.2. The Effect of the Van Hiele Instructional Model on Students' Achievement in Circle Geometry Concepts. Table 5 shows that the posttest mean scores of both the experimental and control groups are 56.36 and 37.51, respectively. The standard deviations are 18.89 and 19.39 (rounded to two decimal places) for the experimental and control groups, respectively. The standard error of the mean of 2.987 and 3.278 reflects the degree of accuracy of the mean for the data collected.

Although the descriptive statistics show that the experimental group outperformed the control group in the posttest, the significance of this difference using the independent sample $t$-test is shown in Table 6 .

Table 6 shows a highly significant Levene's test with a $p$ value of 0.883 which is greater than the significance level of 0.05. It is thus justifiable to conclude that the variances of the posttest scores of the two groups are equal. Moreover, the $p$ value of the independent sample $t$ test for equal variances assumed is less than 0.05 and hence the test is significant $\left(t_{73}=4.257, p<0.05\right)$. This implies that the null hypothesis of no statistically significant difference between posttest mean scores of both the control and experimental groups is rejected in favor of the alternate hypothesis. It can therefore be concluded that there is a statistically significant difference between the posttest mean scores of the two groups in favor of the experimental group. This difference is a result of the 
TABLE 2: Item analysis of level 0 for all participants.

Test item Number of students with correct answers $(N)$ Percentage (\%) $\quad$ Number of wrong answers $(N)$ Percentage $(\%)$ Total $(N)$

\begin{tabular}{lccccc}
\hline 1 (a) & 18 & 24.0 & 57 & 57.0 & 75 \\
$2(\mathrm{a})$ & 6 & 8.0 & 69 & 92.0 & 75 \\
3 (a) & 7 & 9.3 & 68 & 90.7 & 75 \\
\hline
\end{tabular}

Source: Field Data (2019).

TABle 3: Item analysis of level 1 for all participants.

\begin{tabular}{|c|c|c|c|c|c|}
\hline Test item & Number of correct answers $(N)$ & Percentages (\%) & Number of wrong answers $(N)$ & Percentages (\%) & Total $(N)$ \\
\hline $1(\mathrm{~b})$ & 61 & 81.3 & 14 & 1.8 & 75 \\
\hline 2 (b) & 5 & 6.7 & 70 & 93.3 & 75 \\
\hline $3(b)$ & 37 & 49.3 & 38 & 50.1 & 75 \\
\hline
\end{tabular}

Source: Research Field (2019).

TABLE 4: Item analysis of level 2 for all participants.

\begin{tabular}{|c|c|c|c|c|c|}
\hline $\begin{array}{l}\text { Test } \\
\text { item }\end{array}$ & $\begin{array}{c}\text { Number of students with correct } \\
\text { answers }(N)\end{array}$ & $\begin{array}{l}\text { Percentages } \\
(\%)\end{array}$ & $\begin{array}{c}\text { Number of students with wrong } \\
\text { answers }(N)\end{array}$ & $\begin{array}{c}\text { Percentages } \\
(\%)\end{array}$ & Total $(N)$ \\
\hline $1(\mathrm{c})$ & 13 & 17.3 & 62 & 82.7 & 75 \\
\hline $2(c)$ & 11 & 14.7 & 64 & 85.3 & 75 \\
\hline $3(\mathrm{c})$ & 5 & 6.7 & 70 & 93.3 & 75 \\
\hline
\end{tabular}

Source: Research Field (2019).

TABLE 5: Descriptive statistics of posttests scores for experimental and control groups.

\begin{tabular}{llccc}
\hline Group & $N$ & Mean & Std. deviation & Std. error mean \\
\hline Experimental & 40 & 56.36 & 18.888 & 2.987 \\
Control & 35 & 37.51 & 19.393 & 3.278 \\
\hline
\end{tabular}

intervention which facilitated the learning of circle geometry in the experimental group. Finally, the average scores of the participants in the experimental group are indicated to be 18.844 more than that of those in the control group.

Effect size (ES) results show the effectiveness of the intervention.

$$
\mathrm{ES}=\frac{\bar{x}_{\text {exp }}-\bar{x}_{\text {control }}}{\mathrm{SD}_{\text {pooled }}}
$$

where

$$
\begin{aligned}
\mathrm{SD}_{\text {pooled }} & =\sqrt{\frac{\left(n_{\text {exp }}-1\right)\left(\mathrm{SD}_{\text {exp }}\right)^{2}+\left(n_{\text {control }}-1\right)\left(\mathrm{SD}_{\text {control }}\right)^{2}}{n_{\text {exp }}+n_{\text {control }}-2}} \\
\mathrm{SD}_{\text {pooled }} & =\sqrt{\frac{(40-1)(18.88)^{2}+(35-1)(17.25)^{2}}{40+35-2}} \\
& =\sqrt{\frac{24018.85}{73}} \\
& =\sqrt{329.03} \\
& =18.14 .
\end{aligned}
$$

Therefore,

$$
\begin{aligned}
E S & =\frac{56.36-37.52}{18.14} \\
& =\frac{18.84}{18.14} \\
& =1.038 \\
& \approx 1.04 .
\end{aligned}
$$

\subsection{The Effect of the Van Hiele Instructional Model in Facilitating the Learning of Circle Geometry Concepts}

3.3.1. Classroom Observation. During the intervention in the experimental group, the students were taught the concept of circle geometry using the Van Hiele instructional model. The students researched, tried, explored, and presented before their colleagues the concepts of circle geometry after investigating the theorems with their mathematical instruments. Moreover, they asked questions and were also able to answer questions during the lessons that showed or demonstrated their understanding of the concepts that were being taught. The teacher was a guide during the lessons instead of just lecturing the students. Therefore, the items on the Van Hiele Observation Checklist 


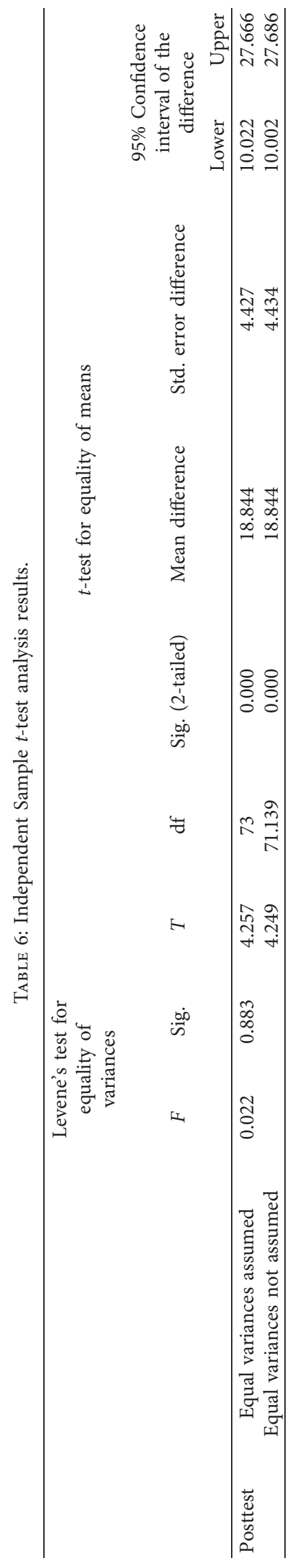


TABLE 7: Item analysis of level 0 for experimental group.

\begin{tabular}{|c|c|c|c|c|c|}
\hline $\begin{array}{l}\text { Test } \\
\text { item }\end{array}$ & $\begin{array}{l}\text { Number of students. with correct answers } \\
(N)\end{array}$ & $\begin{array}{c}\text { Percentage } \\
(\%)\end{array}$ & $\begin{array}{l}\text { Number of students with wrong answers } \\
(N)\end{array}$ & $\begin{array}{l}\text { Percentage } \\
(\%)\end{array}$ & Total $(N)$ \\
\hline 1 (a) & 35 & 87.5 & 5 & 12.5 & 40 \\
\hline 2 (a) & 30 & 75.0 & 10 & 25.0 & 40 \\
\hline 3 (a) & 33 & 82.5 & 7 & 17.5 & 40 \\
\hline
\end{tabular}

Source: Field Data (2019).

TABLE 8: Item analysis of level 1 for the experimental group.

\begin{tabular}{|c|c|c|c|c|c|}
\hline $\begin{array}{l}\text { Test } \\
\text { item }\end{array}$ & $\begin{array}{l}\text { Number of students with } \\
\text { correct answers }(N)\end{array}$ & Percentage (\%) & $\begin{array}{c}\text { Number of students } \\
\text { with wrong answers }(N)\end{array}$ & $\begin{array}{l}\text { Percentage } \\
(\%)\end{array}$ & Total $(N)$ \\
\hline $1(\mathrm{~b})$ & 30 & 75.0 & 10 & 25.0 & 40 \\
\hline $2(b)$ & 29 & 72.5 & 11 & 27.5 & 40 \\
\hline $3(b)$ & 24 & 60.0 & 16 & 40.0 & 40 \\
\hline
\end{tabular}

Source: Field Data (2019).

TABLE 9: Item analysis of Level 2 for the experimental group.

\begin{tabular}{|c|c|c|c|c|c|}
\hline $\begin{array}{l}\text { Test } \\
\text { item }\end{array}$ & $\begin{array}{l}\text { Number of students with } \\
\text { correct answers }(N)\end{array}$ & Percentage (\%) & Number of wrong answers $(N)$ & $\begin{array}{l}\text { Percentage } \\
(\%)\end{array}$ & Total $(N)$ \\
\hline $1(\mathrm{c})$ & 20 & 50.0 & 20 & 50.0 & 40 \\
\hline $2(\mathrm{c})$ & 28 & 70.0 & 12 & 30.0 & 40 \\
\hline $3(\mathrm{c})$ & 21 & 52.5 & 19 & 47.5 & 40 \\
\hline
\end{tabular}

Source: Field Data (2019).

(Appendix B) mostly were checked "yes" for this group during the classroom observation.

3.4. Posttest Data Analysis. Table 7 shows that out of the 40 participants, $35(87.5 \%)$ answered correctly subtest (a) of question one (1). Also, 30 (75\%) answered correctly subtest (a) of question two (2). Finally, 33 (representing 82.5\%) answered correctly subtest (a) of questions three (3).

Table 8 shows that out of the 40 participants, 30 (75\%) answered correctly subtest (b) of question one (1). Also, 29 $(72.5 \%)$ answered correctly subtest (b) of question two (2). Finally, 24 (representing 60\%) answered correctly subtest (b) of questions three (3).

Table 9 shows that out of the 40 participants, 20 (50\%) answered correctly subtest (c) of question one (1). Also, 28 (70\%) answered correctly subtest (c) of question two (2). Finally, 21 (representing 52.5\%) answered correctly subtest (c) of questions three (3). As mentioned earlier, subtest " $c$ " tested somewhat up to level 3 of Van Hiele's Model.

3.5. Findings. An analysis of the marked scripts revealed that most participants were at the prerecognition level of the Van Hiele geometric thinking level before formal instruction: VHIM in the experimental group and traditional approach in the control group.

In addition, the results of the data analysis revealed that the thinking level of the students increased from the prerecognition level to at least level two. This is because there was a statistically significant difference in the average scores of the students in the experimental group after the intervention. Thus, the VHIM did influence active classroom participation and facilitated the learning of circle geometry.

Finally, the results also indicated that the VHIM facilitated learning and improved the geometric thinking of students in the experimental group from the prerecognition level to at least level 2. The researcher observed that the Van Hiele teaching approach made all the difference in the sense that the majority of the students in the experimental group attempted their homework intelligently and were more logical in all presentations.

\section{Discussion}

(1) The analysis from the marked scripts as supported by Tables 2-4 indicated the following:

(i) The students performed poorly in the subitem (a) of questions 1,2, and 3 (Table 2). The analysis revealed that the majority of the students could not tell by visualization how many quadrilaterals are in the figure presented in question one (1). Moreover, most students could not identify line $\mathrm{BO}$ as a tangent in question two (2). Finally, most students could not identify the line PR as a diameter as required in question three (3).

(ii) The students performed fairly well in the subtest (b) of question 1 but not questions 2 and 3 (Table 3 ). The analysis from the marked scripts showed that most students were able to draw out AOCD but could not label or identify it as a kite. 


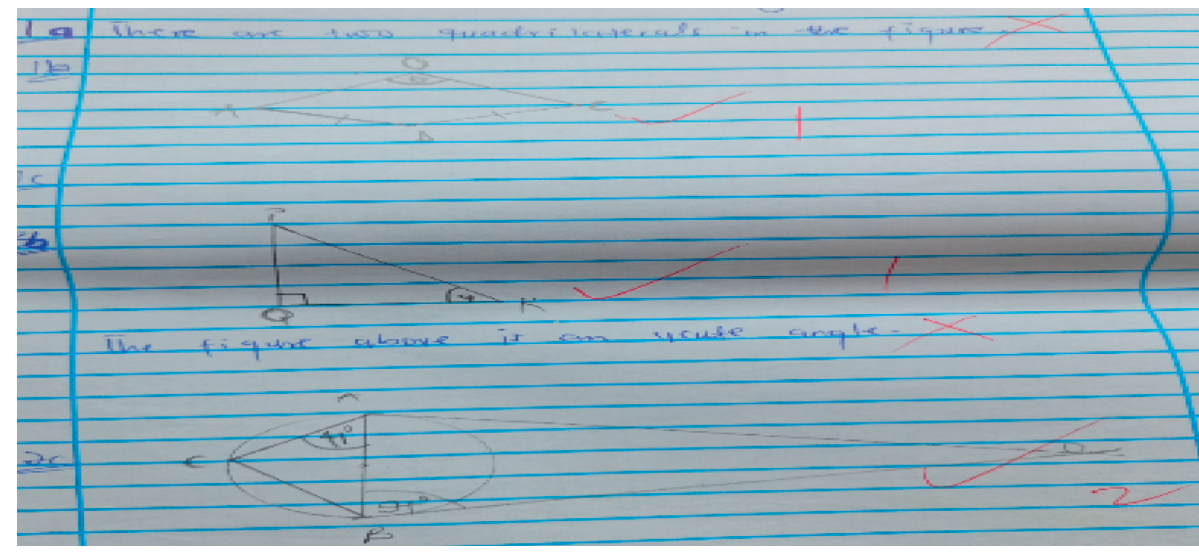

FIGURE 1: A pretest sample marked script of a study participant.

Moreover, most students could not draw or identify PQR as a right-angled triangle. Finally, most students who drew triangle PQR could not properly label it.

(iii) The students performed poorly in subtest (c) of questions 1, 2, and 3 (Table 4). That is, the majority of the study participants could not express $<\mathrm{ABC}$ in terms of $\theta$ in question one (1). Also, most students could not show either by construction or proof that $|\mathrm{AO}|=|\mathrm{BO}|$. Finally, almost all the study participants could not find the angle $\propto$ in terms of $\beta$ in question three (3). The analysis above reveals that most students' participants did not have the knowledge enough (as Van Hiele level 0 demands) to identify by visualization shapes (inscribed) in connection with circle geometry. Figure 1 is a pretest sample marked script of a study participant.

These results concur with the work of Sadiki [18] which aimed at finding out the effect of using Van Hiele's instructional model in the teaching of congruent triangles in grade 10 in Gauteng, South Africa, where the majority of the students were found to be at the prerecognition level of the Van Hiele geometric thinking level.

In this research, the number of students who passed question category (a) (which tested visualization) of each test item was less than the number of students who passed question category (b) (which tested identification) of the same question. The possible reason is that even though participants who answered the questions could draw out shapes from a given diagram, they had limited knowledge about quadrilaterals, cyclic quadrilaterals, shape identification, and naming which is the required knowledge for answering the subquestions "(a)". For example, in subquestion (b) of question 1, the majority of the students were able to draw out the shape as a four-sided figure but could not name it as a kite. Thus, there was a gap in the study participants' knowledge of basic geometry concepts. The sample script in Figure 1, for example, shows that the participant like many others was able to answer subquestion "c" of question 3 by construction and not through deductive proof as required by Van Hiele level 3. Moreover, it is evident from the script that the study participant could draw out the shapes required by subquestions "b" of each question item but could not name the same. This explains the seemingly high scores by the students in subquestions "b" of almost all the test items. This result is in agreement with the result of a study by Asemani et al. [9]. In their research, [9] measured Van Hiele's levels of geometric thinking attained by Ghanaian final year (SHS 3) students before leaving school. Out of the 200 students who participated, the results indicated that $42.5 \%$ were at the prerecognition level.

(2) The paired sample, the independent sample $t$-test, and the effect size calculations were used to determine the effect of the Van Hiele instructional model on students' achievement. The paired sample $t$-test indicated a significant difference in the pretest and posttest scores of the experimental group as a result of the intervention. This result indicated that the students improved from the prerecognition level to a higher level.

The Van Hiele instructional model improved the achievement scores of students in the experimental group in circle geometry. This finding is consistent with the work of Erdoğan et al. [19] who concluded that the Van Hiele model improved students' scores among fifty-five (55) 6th-grade primary school learners in Bolu, Turkey. According to them, instructions carried out according to the Van Hiele instructional model require that students research and explore geometric concepts. This means the Van Hiele-based instruction unlike the teacher-centered traditional approach is student-centered and hence effective in making learning fascinating as well as improving students' achievement scores. 
(3) The results from the analysis of the classroom observation and posttest demonstrate that the intervention facilitated the learning of the concepts of circle geometry.

Firstly, the learners in the experimental group were attentive during lessons and so could reproduce the concepts learned compared to their counterparts in the control group. This means the students in the experimental group were motivated to learn compared to those taught according to the traditional approach. This can be attributed to the classroom practices implemented according to the Van Hiele protocols. Perhaps, that is why Papanstasiou as cited by Serebour [20] asserted that students' classroom practices are strong factors that enhance students' mathematics achievement. Hence, the Van Hiele model classroom instructional protocols that were followed in the experimental group helped to facilitate the learning of circle geometry concepts.

Moreover, although most students within both groups chose to prove by construction rather than deductive proof when given the two options in one of the posttest questions, the experimental group indicated a better conceptual understanding in terms of their presentations and organization of their thoughts in circle geometry. Their constructions were clearer and on point. This result is in agreement with Rose and Airline cited by Oladosu [10] who asserted that students demonstrate a better conceptual understanding when they undergo lessons guided by the Van Hiele instructional model.

Finally, unlike the students in the control group, the students in the experimental group proved to have improved in classroom discussions, presentations, and understanding with higher geometric thinking in relation to the concepts of circle geometry. They tried and answered correctly the questions that demanded a higher cognitive attitude. Thus, the Van Hiele thinking level of the students increased from prerecognition level to at least level two (2). The above result is also supported by the works of Erdoğan et al. [19], Siew et al. [21], and Jogymol et al. [22] who concluded that learning is facilitated among students taught according to the Van Hiele model compared with those taught with the traditional approach.

\section{Conclusions}

Conclusively, the findings in this study indicate that teachers should determine students' geometric thinking level before geometric instructions are carried out. This is because a student cannot move to higher levels of geometry without going through lower levels. Furthermore, a diligent implementation and integration of VHIP protocols instead of the traditional approach in the classroom will make the learning of geometry more lively, engaging, and fascinating for students. Finally, if the Van Hiele instructional model is effected in the teaching of circle geometry in the SHS2 (grade 11) mathematics classroom, it will facilitate the process of learning geometric concepts taught and improve the achievement scores and geometric thinking levels of the learners.

\section{Appendix}

\section{A. Classroom Observation Checklist (Designed by Researcher according to the Van Hiele Instructional Model)}

Observer:
Research

Date of Observation:

Time:

Scale: Yes, No, or N/A (Please note: N/A means Not Applicable)

(A) Classroom Organisation: Yes, No, or N/A

(1) The classroom is very spacious

(2) Learners are comfortably seated.

(3) The board is a white marker board

(4) Participants were seated in groups

(B) Lesson Presentation

(1) Teacher begins class at the appropriate time.

(2) Materials presented are appropriate to the level of learners

(3) Materials presented are related to the objectives of the learning area.

(4) Teaching Approach

(C) Lesson Presentation Procedure

(1) Teacher already informed the study participants about the topic to be taught prior to the lesson to allow learners to research about it.

(2) Teacher postquestions to determine the geometric thinking level of the study participants

(3) Teacher gives classwork to be discussed in each group.

(4) Teacher introduces the day's topic and gives a brief explanation on the topic for clarification.

(5) Teacher gives a more cognitive demanding classwork to be solved by study participants.

(6) Teacher allows the study participants to demonstrate their geometric thinking abilities and also goes around the class to see what each group were doing, correct them, confirm their solution approaches or give more explanation.

(7) Teacher allows the study participants to explain how each group went about solving the problem, 
while the teacher and other learners ask questions.

(8) Teacher gives exercises and/or homework

(D) Students

(1) Students pay attention in class.

(2) Students answer questions during lessons

(3) Students ask questions for clarity.

(4) Students are able to do their homework/ exercises.

\section{B. Test}

(1) In the figure below, $O$ is the center. $\mathrm{AD}=\mathrm{DC}$ and $<\mathrm{AOC}=\theta$.

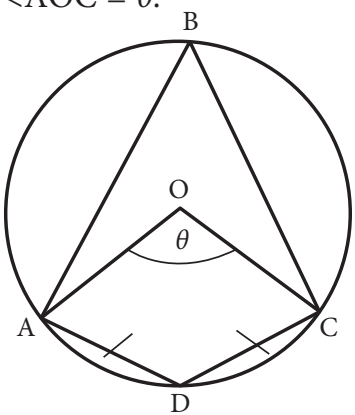

(a) How many quadrilaterals are in the figure above?

(b) Identify and draw out AOCD.

(c) Express $<\mathrm{ABC}$ in terms of $\theta$.

(2) Consider the diagram below, $\mathrm{AO}$ and $\mathrm{BO}$ are straight lines that meet the circle at $\mathrm{A}$ and $\mathrm{B}$, respectively.

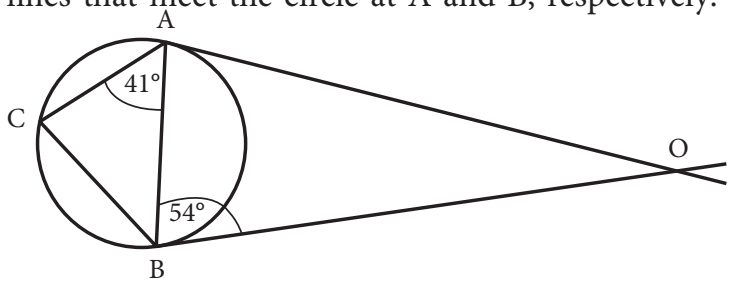

(a) Identify line BO.

(b) Find $<\mathrm{ABC}$.

(c) Show either by construction or proof that $|\mathrm{AO}|=|\mathrm{BO}|$.

(Clue: Assume $\mathrm{AB}$ passes through the center)

(3) In the diagram, $O$ is the center of the circle and $\angle \mathrm{POQ}=90^{\circ}$

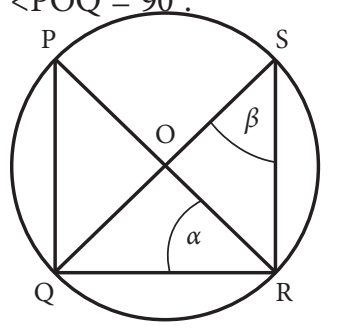

(a) Identify PR

(b) Identify the figure labeled PQR and draw it out.

(c) Find $\propto$ in terms of $\beta$.

\section{Data Availability}

The data (primary) supporting the results of this study are within the article.

\section{Conflicts of Interest}

The authors declare that there are no conflicts of interest and the result is not influenced by any secondary interest.

\section{Acknowledgments}

The authors thank the staff at the Department of Mathematics Education, University of Education, Winneba, Ghana, Mathematics and Statistics Department of the University of Energy and Natural Resources, Ghana, and staff and students of Daffiama Senior High School, in the Daffiama-Bussie-Issa District of the Upper West Region in Ghana for their support and kindness during the period this paper was written.

\section{Supplementary Materials}

First part is the pre-test scores of All 75 students. Second part is the post-test scores of the experimental group and control group. (Supplementary Materials)

\section{References}

[1] CRDD, Mathematics Syllabus for Senior High Schools, Ghana Education Service, Accra, Ghana, 2010.

[2] Ministry of Education Science and Sports, Teaching Syllabus for Core Mathematics (Senior High School), Curriculum Research and Development Department, Accra, Ghana, 2010.

[3] T. Adolphus, "Problems of teaching and learning of geometry in secondary schools," Retrieved from International Journal for Emerging Sciences, vol. 1, no. 2, pp. 143-152, 2011.

[4] National Curriculum Framework, The National Curriculum Framework, GES, Accra, Ghana, 2018.

[5] WAEC, Chief Examiners Report, http://www.waecgh.org/ examiners-report, The West African Examination Council, Lagos, Nigeria, 2014, http://www.waecgh.org/examinersreport.

[6] WAEC, Chief Examiners' Report, http://www.waecgh.org/ examiners-report, The West African Examination Council, Lagos, Nigeria, 2015, http://www.waecgh.org/examinersreport.

[7] WAEC, Chief Examiners' Report, http://www.waecgh.org/ examiners-report, The West African Examination Council, Lagos, Nigeria, 2016, http://www.waecgh.org/examinersreport.

[8] P. M. Van Hiele, "Developing geometric thinking through activities that begin with play," Teaching Children Mathematics, vol. 5, no. 6, pp. 310-316, 1999.

[9] E. Asemani, S. Aseidu-Addo, and R. A. Oppong, "The geometric thinking levels of senior high school students in Ghana," European American Journals, vol. 5, no. 3, 2017.

[10] L. Oladosu, Secondary School Students' Meaning and Learning of Circle Geometry, Graduate Studies/The Vault: Electronic Thesis and Dissertations, University of Calgary, Calgary, Canada, 2014, http://prism.ucalgary.ca/handle/11023/1735. 
[11] P. M. Van Hiele, Structure and Insight: A Theory of Mathematic Education, Academic Press, Orlando, FL, USA, 1986.

[12] A. H. Abdullah and E. Zakaria, "The effects of Van Hiele's phase-based instruction using the geometer's sketchpad (GSP) on students' levels of geometric thinking," Research Journal of Applied Sciences, Engineering and Technology, vol. 5, no. 5, pp. 1652-1660, 2013.

[13] I. Vojkuvkova, "The van Hiele model of geometric thinking," in Proceedings of the Contributed Papers (WDS'12), vol. 1, pp. 72-75, Prague, Czech Republic, May 2012.

[14] L. Cohen, L. Mannion, and K. Morrison, Research Methods in Education, Routledge/Falmer, London, UK, 2007.

[15] J. Fraenkel and N. Wallen, How to Design and Evaluate Research, McGraw-Hill Inc., New York, NY, USA, 2003.

[16] Z. Usiskin, Van Hiele Levels and Achievement in Secondary School Geometry: Congnitive Development and Achievement in Secondary School Geometry Project, University of Chicago Press, Chicago, IL, USA, 1982.

[17] E. Baffoe and D. Mereku, "The Van Hiele levels of understanding of students entering senior high school in Ghana," African Journal of Educational Studies in Mathematics and Sciences, vol. 8, no. 1, 2010.

[18] M. Sadiki, The Effect of Using Van Hiele's Instructional Model in the Teaching of Congruent Triangles in Grade 10 in Gauteng High Schools, Pretoria, South Africa, 2016, http://hdl.handle. net/10500/22164.

[19] T. Erdoğan, R. Akkaya, and C. Akkaya, "The effect of the Van Hiele model based instruction on the creative thinking levels of 6th grade primary school students," Educational Sciences: Theory and Practice, vol. 9, no. 1, pp. 181-194, 2009.

[20] O. K. S. Serebour, Factors Teachers, Students and Parents Perceive as Influencing JHS Students' Mathematics Learning, MPhil Thesis, UCC, Cape Coast, Ghana, 2013.

[21] N. Siew, C. Chong, and M. Abdullah, "Facilitating students ${ }^{\mathrm{TM}}$ geometric thinking through Van Hiele ${ }^{\mathrm{TM}} \mathrm{S}$ phase-based learning using tangram," Journal of Social Sciences, vol. 9, no. 3, pp. 101-111, 2013.

[22] K. Jogymol, S. Walter, and M. Kuttickattu, "Lessons learnt from employing van Hiele theory based instruction in senior secondary school geometry classrooms," Eurasia Journal of Mathematics, Science and Technology Education, vol. 12, no. 8, pp. 2223-2236, 2016. 